\title{
Editorial
}

Journal of Innate

Immunity

\section{Innate Immunity of the Lung}

\author{
Catherine M. Greene ${ }^{a}$ Pieter S. Hiemstra ${ }^{b}$ \\ a Department of Clinical Microbiology, Royal College of Surgeons in Ireland, Beaumont Hospital, Dublin, Ireland; \\ ${ }^{\mathrm{b}}$ Department of Pulmonology, Leiden University Medical Center, Leiden, The Netherlands
}

An effective innate immune system protects the lung from inhaled pathogens and toxicants, but is also known to contribute to acute and chronic inflammatory lung diseases. In this themed issue of the Journal of Innate Immunity, the innate immune system of the lung takes center stage in 4 review papers and 5 original research papers. These papers demonstrate our rapidly increasing insight into innate immunity in the lung, as well as the challenges ahead to better exploit this knowledge for new treatments of common and rare lung diseases.

In her review, Kikkert [1] discusses the arms race between host innate immunity and evasion of this immunity by respiratory viruses. Infections with respiratory viruses such as influenza, rhinovirus, and respiratory syncytial virus are an important problem in the general population, as well as in subjects with chronic lung diseases such as asthma and chronic obstructive pulmonary disease (COPD), whereas infection with corona viruses (CoVs) such as SARS-CoV and MERS-CoV, and bird flucausing avian influenza have made the headlines in the media in recent years. Suppression of antiviral defenses is a strategy employed by most viruses, and insight into the mechanisms underlying this evasion is essential to better prevent and treat respiratory viral infections. With a focus on RNA viruses, she illustrates how viruses escape recognition by intracellular sensors, use enzymatic activity to suppress innate immunity, and how viruses manipulate the ubiquitin system. One of the mechanisms by which pathogens can be cleared is autophagy, and the role

\section{KARGER}

E-Mail karger@karger.com www.karger.com/jin
(C) 2019 The Author(s) Published by S. Karger AG, Basel

Karger Open access

This article is licensed under the Creative Commons AttributionNonCommercial-NoDerivatives 4.0 International License (CC BYNC-ND) (http://www.karger.com/Services/OpenAccessLicense). Usage and distribution for commercial purposes as well as any distribution of modified material requires written permission. of autophagy in innate immunity is the topic of the review by Rao and Eissa [2]. This intracellular digestion system not only contributes to host defense against respiratory infection, but is also essential for maintaining cellular function by degrading macromolecules and dysfunctional organelles, and by generating nutrients in case of nutrient starvation. Dysfunction of autophagy leads to accumulation of misfolded proteins and damaged organelles in stressed cells, which may result in inflammation. This review serves both as an introduction to autophagy as an intracellular recycling system, as well as a detailed discussion of its relation to lung innate immunity including the way it controls unwanted activation of the inflammasome. The discussion on how some pathogens may evade clearance by autophagy stresses the role of autophagy in host defense against infection, and further broadens the scope of mechanisms discussed by Kikkert [1] that allow viruses to escape cellular defense systems.

Metabolic reprogramming in innate immunity and how it contributes to a variety of lung diseases is the focus of the review by Michaeloudes et al. [3]. It builds on pioneering studies showing the role of cellular metabolism and its reprogramming in cancer and innate immunity. Metabolic changes are induced during activation of the innate immune system, but also employed by micro-organisms to escape defense. A shift to glycolysis at the expense of oxidative phosphorylation is especially characteristic of proinflammatory polarization of macrophages and dendritic cells. These changes allow for adaptation to
Dr. Pieter S. Hiemstra

Department of Pulmonology, Leiden University Medical Center P.O. Box 9600

NL-2300 RC Leiden (The Netherlands)

E-Mail p.s.hiemstra@lumc.nl 
their pro-inflammatory function, including mediator production and killing of pathogens. Importantly, the authors demonstrate how deregulation of metabolic reprogramming in asthma and COPD may contribute to dysregulated innate immunity. The therapeutic potential of this area of research is strengthened by the availability of drugs that target metabolic pathways and that are being evaluated in cancer trials, for example.

Following their introduction as new kids on the block a decade ago, the role of the various subsets of innate lymphoid cells (ILCs) in immunity and pathogenesis of lung diseases is now widely recognized and studied. van der Ploeg et al. [4] discuss the role of ILC2 in human lung diseases. They describe the development and tissue localization of ILC2, their regulation and plasticity, and neuronal and metabolic control of these cells. Next, insight is provided into their role in immunity and lung diseases such as asthma, COPD, lung fibrosis, and cystic fibrosis, based on lessons learned from animal models and human studies. In their outlook, they refer to promising results of studies targeting type 2 immunity driven by ILC2 in allergic airway diseases.

Following this series of reviews covering various aspects of innate immunity of the lung, and elaborating on themes such as escape mechanisms allowing pathogens to evade innate immunity, the role of metabolic reprogramming, and therapeutic prospects of unravelling innate immunity, this issue of the Journal of Innate Immunity also includes 5 original research papers focused on epithelial cells, macrophages, and monocytes. Microbial recognition is central in innate immunity to respiratory infection, and Toll-like receptors (TLR) are an essential part of the pulmonary toolbox of innate immunity that enables it to sense pathogen presence. Grassin-Delyle et al. [5] studied expression and function of TLRs on human lung macrophages isolated from resected lung tissue. Expression of the diverse repertoire of TLRs and response to subtypespecific TLR agonists revealed a remarkably wide spectrum. Interestingly, little interpatient variation was observed in TLR expression levels, with the exception of TLR8. M1 polarization was not only observed in response to LPS, but also to a range of other TLR agonists. The use of primary human macrophages isolated from resected lung tissue is a particular strength of this study, revealing important differences with, for example, studies using lung macrophages derived from mice. In addition to macrophages and other lung cells, the airway epithelial cells that line the airway lumen also use a range of TLRs to monitor microbial presence at the epithelial surface, and this may lead to an enhanced production of antimicrobial pep- tides (AMPs) that serve as effector molecules of innate immunity by killing micro-organisms, modulating immunity, and enhancing wound repair. Importantly, vitamin D is now also recognized as a regulator of production of selected AMPs such as the human cathelicidin LL-37. Schrumpf et al. [6] used differentiated cultures of airway epithelial cells to show that vitamin D increases the production of AMPs such as hCAP18/LL-37, but that this is reduced by TGF- $\beta 1$. Expression of the multifunctional cytokine and growth factor TGF- $\beta 1$ is increased in various lung diseases, including COPD. They went on to show that TGF- $\beta 1$ modulates epithelial cell metabolism of vitamin D by increasing expression of the vitamin $\mathrm{D}$-degrading enzyme CYP24A1, and also reduces the expression of a range of constitutively produced host defense molecules in part by skewing epithelial differentiation towards a reduction in secretory cells. One of the host defense molecules that was regulated by TGF- $\beta 1$ in the study of Schrumpf et al. [6], the antimicrobial proteinase inhibitor secretory leucoprotease inhibitor (SLPI), is the central research topic of the study by McKiernan et al. [7]. SLPI, which also displays immunomodulatory effects, is not only produced by epithelial cells, but also by monocytes, amongst others. Sexrelated differences in chronic inflammatory diseases and susceptibility to respiratory infections are the background of their study. They demonstrate that estrogen decreases the expression of SLPI by monocytes, and provide evidence that this is mediated by an increase in miR-19. Thereby, they delineate one of the mechanisms by which estrogen modulates the innate immune system.

Toll-interacting protein (Tollip) is an adaptor protein that is a negative regulator of TLR and IL- 1 receptor signaling. Dakhama et al. [8] studied the role of Tollip in rhinovirus infection in a type 2 cytokine environment to mimic conditions in allergic asthma, where rhinovirus contributes to exacerebations. Tollip was previously found to control activation of IRAK1, which acts downstream not only of TLRs and the IL-1 receptor, but also mediates signaling of the IL-33 receptor ST2. Using human primary epithelial cells and mouse models, they showed how Tollip restricts IL-8 production in response to rhinovirus infection in the presence of type 2 allergic inflammatory conditions, and demonstrated involvement of Tollip in the production of soluble ST2 that can restrict the activity of IL-33. Finally, the study by Yue et al. [9] also focused on a type 2 cytokine environment and epithelial cells. They studied the regulation of inflammatory cytokines and mucus production by nasal epithelial cells in allergic rhinitis. The type 2 cytokine IL-13 is a well-known inducer of mucin production in epithelial 
cells, and Yue et al. [9] demonstrated that the long noncoding RNA Linc00632 blocks IL-13 induced GM-CSF, eotaxin, and MUC5AC production by targeting miR-498. Importantly, they found that Linc00632 is decreased in nasal mucosal tissues from patients with allergic rhinitis and in IL-13-treated epithelial cells.

The series of articles in this issue of the journal demonstrates the breath of research on innate immunity in the lung and its implications for understanding the development and progression of a range of lung diseases. It also highlights various aspects of innate immunity in the lung and how these can be influenced by and exert influence on other mechanisms including cellular metabolism. The clinical implications of this research include identification of targets for innovative treatment strategies to better prevent and treat the respiratory diseases that affect so many patients worldwide.

\section{Disclosure Statement}

The authors have no conflicts of interest to declare.

\section{References}

1 Kikkert M. Innate Immune Evasion by $\mathrm{Hu}$ man Respiratory RNA Viruses. J Innate Immun. DOI: 10.1159/000503030.

2 Rao L, Eissa NT. Autophagy in Pulmonary Innate Immunity. I Innate Immun. DOI: $10.1159 / 000497414$.

3 Michaeloudes C, Bhavsar PK, Mumby S, Xu B, Hui CKM, Chung KF, et al. Role of metabolic reprogramming in pulmonary innate immunity and its impact on lung diseases. J Innate Immun. DOI: 10.1159/000504344.

4 van der Ploeg EK, Carreras Mascaro A, Huylebroeck D, Hendriks RW, Stadhouders R. Group 2 Innate Lymphoid Cells in Human Respiratory Disorders. J Innate Immun. DOI: 10.1159/000496212.
5 Grassin-Delyle S, Abrial C, Salvator H, Brollo M, Naline E, Devillier P. The Role of Toll-Like Receptors in the Production of Cytokines by Human Lung Macrophages. J Innate Immun. DOI: $10.1159 / 000494463$.

6 Schrumpf JA, Ninaber DK, van der Does AM, Hiemstra PS. TGF- $\beta 1$ Impairs Vitamin D-Induced and Constitutive Airway Epithelial Host Defense Mechanisms. J Innate Immun. DOI: 10.1159/000497415.

7 McKiernan PJ, Smith SGJ, Durham AL, Adcock IM, McElvaney NG, Greene CM. The Estrogen-Induced miR-19 Downregulates Secretory Leucoprotease Inhibitor Expression in Monocytes. J Innate Immun. DOI: 10.1159/ 000500419 .
8 Dakhama A, Al Mubarak R, Pavelka N, Voelker D, Seibold M, Ledford JG, et al. Tollip Inhibits ST2 Signaling in Airway Epithelial Cells Exposed to Type 2 Cytokines and Rhinovirus. J Innate Immun. DOI: 10.1159/ 000497072.

9 Yue L, Yin X, Hao F, Dong J, Ren X, Xu O, et al. Long Noncoding RNA Linc00632 Inhibits Interleukin-13-Induced Inflammatory Cytokine and Mucus Production in Nasal Epithelial Cells. J Innate Immun. DOI: 10.1159/ 000500420 . 